\title{
The contribution of vocational training to employment, job-related skills and productivity: evidence from Madeira
}

\author{
Santiago Budría and \\ Pedro Telhado-Pereira
}

\begin{abstract}
In this paper, we analyse the transition to the labor market of participants in vocational training in Madeira in Portugal. The analysis is in two stages. First, we investigate how the employment status at different dates (1 month, 1 year, and 2 years after the completion of the training program) depends on relevant variables, such as age, gender, education and the content and duration of the training. Second, we use individuals' selfassessment of the effectiveness of the training program along three dimensions: employment, job-related skills and productivity. The respondents score training activities high on every dimension. Moreover, we find that training is more effective among the educated, indicating that vocational training is far from being remedial. We also find that long training programs and training related to tourism are particularly effective.
\end{abstract}

\section{Introduction}

Education is a scarce and valuable good in the Portuguese labor market. Among European Union Member States, Portugal is the country with the lowest schooling

$\square$ Santiago Budría, Assistant Professor, Department of Economics, University Pablo de Olavide, Ctra. Utrera km. 1, 41013 Sevilla, Spain. Email: sbudrod@upo.es

We are indebted to the Direcção Regional de Formação Profissional in Madeira and, particularly, to Maria João Freitas and Ricardo Figueira for providing the dataset. We thank seminar participants at the European Research Network on Transition in Youth Conference Workshop. 
levels and the highest returns to education (Martins \& Pereira, 2004; Vieira, 1999). This evidence has lead governments and institutions to support the implementation of policies aimed at increasing the country's average level of education (CNCLSTP, 2006; OECD, 2005). However, the traditional schooling system is not a real option for many workers. For old and poorly educated workers as well as for individuals who dropped out of school, training is, for the most part, the only way to upgrade skills and acquire new competencies. In line with this view, the latest OECD Economic Survey for Portugal states that the participation of adults in training activities should be stimulated, by targeting support toward needy groups, enhancing the quality of training courses and evaluating the effectiveness of existing programs' (OECD, 2006).

At the international level, a number of studies have made progress in the task of assessing the impact of training activities on different labor market outcomes, including wages (Lynch, 1992; Pischke, 2001), productivity (Bartel, 1995; Black \& Lynch, 1996; Conti, 2005; Van Reenan et al., 2006), employment (Jespersen et al., 2008; Richardson \& van den Berg, 2001) and job-related skills (Fitzenberger \& Völterb, 2007). Despite a general conclusion emerging from these studies (i.e. some forms of training among certain population groups are rewarded in the labor market), the results are strongly case dependent and can hardly be transferred across countries and across training schemes. In Portugal, existing research has focused on the relation between wages and training (Budría \& Pereira, 2007; Hartog et al., 2000; Saraiva, 1999), and has disregarded the dimensions of employability, job-related skills and productivity.

In this paper, we take a step toward filling this gap by exploring the contribution of vocational training to three important aspects in labor markets: (1) employment, (2) job-related skills, and (3) productivity. Arguably, these dimensions are also relevant for prospective trainees, employers and policy makers. We use data from the Survey of Insertion (SI) (Inquérito à Inserção), a survey carried out to evaluate the effects of vocational training programs on the transition to the labor market in Madeira, Portugal. The information provided in the survey can be divided into two main blocks. In the first block, individuals are asked to report their employment status at three different dates: 1 month, 1 year, and 2 years after completion of the program. We use this information to explore how the probability of employment depends on the individual characteristics and on the type of vocational program. In the second block, individuals are asked to assess the extent to which the training (1) facilitated their access to employment, (2) was related to their current job, and (3) enhanced their productivity in the job. We use this information to assess the contribution of training along these dimensions and to explore how this contribution differs across groups of workers and across training programs.

Relative to previous work, our analysis presents three main features. First, we explore the effectiveness of training along dimensions (1), (2) and (3) simultaneously. This is an important differentiation, insofar as some types of training may raise productivity and provide fundamental skills but fail to attract new employment opportunities. Inversely, some training activities may promote employment but have a null effect on the workers' productivity. That would be the case if, for example, high ability and more committed individuals undertake training activities to signal their higher quality to employers who, in turn, use training participation as a basis for the decision to offer a contract. If these signaling effects are important, it may well be that once employed, these workers are more productive due not to their training but to their higher ability. By considering different outcomes simultaneously, we examine what forms of training are more effective in a particular dimension.

Second, unlike most other papers, we do not confine the analysis to objective labor market measures. Rather, we include the individuals' subjective evaluation of the training activities. This approach offers a methodological advantage. The typical problem of isolating the impact of training on a particular outcome (e.g. wages, employment rates, job mobility, job offers) is that it is hard to isolate the pure effect of a given covariate (training) from other unobserved factors that are correlated with training and affect the observed outcome (e.g. ability, motivation, tenure). If individuals who receive training are not a random sample, but selected (or self-selected) 
because of some unobservable characteristics, then the estimates might be biased. This argument also applies to selection by subject of study: if high-ability individuals are more prone to choose a specific area, the returns to training in this particular area will be higher because of the higher ability of the trainees and not only because of the content of the training. Although there exist econometric techniques to deal with selectivity issues, the results are typically sensitive to the quality of the instruments and the specification of the participation equation (Bound et al., 1995). Subjective questions, in turn, provide direct information on the variable under scrutiny, do not require auxiliary distributional assumptions and have a straightforward interpretation. Moreover, the returns to training may be obscured if workers from different occupations and employers have different opportunities to reap the benefits of the productivity gains associated with training (Bishop, 1994). If this is the case, asking individuals directly rather than collecting objective measures may result in a more reliable set of information.

Subjective questions have received increasing attention in the literature, as they offer complementary and sometimes unique perspectives on relevant topics. Psychologists and, recently, economists have made ample use of individual assessments to study well-being, quality of life, job satisfaction, welfare and educational mismatches in modern societies. ${ }^{1}$ Similarly, the use of self-report data is a research paradigm within firms and studies evaluating the extent of knowledge acquisition among participants in industrial training (Rowold, 2007; Velada et al., 2007). Up to now, however, the use of subjective questions is infrequent in research focusing on labor markets and, more specifically, on the effects of vocational education on different employment-related outcomes. This is unfortunate, as self-reported measures of satisfaction given by training participants may go a long way toward fulfilling the OECD recommendation of 'evaluating the effectiveness of existing programs' and providing policy makers important clues to improve the national training systems. In order for the training to be effective, post-participation follow-up and feedback from participants are crucial to enable governments and training institutions to improve their own performance. After all, if we sought to know whether or not the training exercise helps participants learn skills and concepts that are applicable to the workplace or improve their employability, the most evident way is to ask them directly. ${ }^{2}$

As a third feature, the paper contributes to the literature on regional economics. Madeira Island is a tourist region and, as such, a core part of its economy is oriented toward this activity. In the regional media, it is frequently argued that training in this strategic sector should facilitate access to employment of young individuals, increase the productivity of incumbent workers, improve the tourist's satisfaction and,

\footnotetext{
${ }^{1}$ For a methodological discussion on the scope of this type of questions and a variety of economic applications, see Frey and Stutzer (2002) and Kahneman et al. (1999) and, more recently, Van Praag and Ferrer-i-Carbonell (2008).

${ }^{2}$ Behind the score reported by a person lies a cognitive assessment of to what extent the training activity is judged in a favorable way. Our position is that individuals can provide such an assessment accurately. We are aware, however, that subjective questions have been the object of some criticism. First, the individual response is liable to various situational influences, such as the site of the interview and the individual's mood. Luckily for us, these differences can be considered as essentially random error, because they tend to disappear as the sample size rises. Second, responses are influenced by the precise wording of questions, answer formats, sequence of questions and context of the interview. Third, self-reported measures may be a reflection of personality traits, circumstances, aspirations and comparisons with others. As a consequence, the observed outcome may depend on latent individual effects that are unobserved by the researcher. These limitations have been long discussed in the literature and, although they may limit the applicability of this type of questions to certain domains, the general consensus is that self-report data can be regarded as valid, reliable and consistent sets of information (see, again, Frey \& Stutzer, 2002; Kahneman et al., 1999). The questionnaires used in this paper were constructed following international standards concerning the wording of questions and the scales used. Moreover, as we explain below, interviews were conducted anonymously, during the same months and among individuals with similar age. Arguably, these ingredients may have contributed to reduce the extent of unobserved heterogeneity and the extent of systematic errors.
} 
ultimately, promote the region in international networks. This paper is the first to examine the extent to which training in the area of Tourism provides individuals with marketable skills, and whether or not training in this area is more effective than training in other areas.

The rest of the paper is organized as follows. The dataset is presented and we report summary statistics of the estimating sample. Next, we describe the transition from vocational training to work in Madeira and outline some interesting patterns. We, then, estimate the determinants of employment at different dates using a set of logit models. After that, we examine individuals' self-assessment of the effectiveness of training in promoting employment, job-related skills and productivity. The results shed further light on the contribution of the different training programs to employment and uncover important differences across groups of workers. The findings of the paper are discussed and some theoretical implications outlined before the authors offer some concluding remarks.

\section{The data}

The SI is a yearly survey conducted by the Regional Directorate of Vocational Training in Madeira (Direç̧ão Regional de Formação Profissional) to evaluate the transition to the labor market of participants in vocational training. In each year, a sample of some 500 individuals who completed a training program in the region is interviewed. Interviews are conducted in July and August, take place 2 years after completion of the program and are conducted only among individuals who were not employed during the training. Participants are asked to report information about their educational background, age and the content and duration of the training activity. They are also asked to report their employment status at three different dates: 1 month, 1 year and 2 years after exit from training. Those who declare that they are employed at the time of the survey $(84.7 \%$ of the sample) are asked to assess the extent to which the training (1) contributed to get the job, (2) was related to the job, and (3) raised their productivity in the job. The choice of a 2-year period is based on the assumption that this time provides a sufficient ground to evaluate the effectiveness of the training program.

For the present study, we use pooled data from the waves 2000 to 2005. After restricting the sample and dropping observations with missing values, we retain 2057 individuals. In Table 1, we present the summary statistics. Men account for a large fraction of the sample (61.4\%, against $38.6 \%$ of women). The distribution across educational levels differs slightly across genders. Relative to men, women are more concentrated toward the tails of the educational distribution. Specifically, the fraction of individuals in the lowest educational category is $0.6 \%$ among men and $7.3 \%$ among women. In turn, the fraction of individuals with secondary and tertiary education is, respectively, $12.7 \%$ and $1.4 \%$ among men and $17.5 \%$ and $2.8 \%$ among women. Notwithstanding this, average years of schooling are similar across genders (10.8 and 10.6 years, respectively). As regards the age distribution, men tend to be younger than women. Specifically, we find that the proportion of individuals aged below 21 is $43.0 \%$ in the male and $26.1 \%$ in the female subsample, whereas these figures are $14.6 \%$ and $26.1 \%$, respectively, when we consider the above- 25 age group. Vocational training in Madeira covers a variety of courses. We have grouped these courses into eight areas: Tourism; Accounting, Business \& Administration; Agricultural Production \& Food Industry; Environment \& Urbanism, Civil Construction; Electronics \& Energy; Applied Computer Sciences; and the residual category 'Others'. Not surprisingly, in Madeira, the most demanded courses are those in Tourism (19.9\% among men and 32.2\% among women). Men are inclined toward Civil Construction (15.4\%), Electronics \& Energy $(12.2 \%)$ and Accounting, Business \& Administration (11.3\%), and rarely enroll in Agricultural Production \& Food Industry (3.3\%). Among women, Accounting, Business \& Administration $(21.4 \%)$ is, after Tourism, the most popular area, whereas Electronics \& Energy $(0.2 \%)$ and Environment \& Urbanism $(0.6 \%)$ are seldom demanded. The 


\begin{tabular}{lrr}
\hline & Men & Women \\
\hline & 61.4 & 38.6 \\
Education level & & 7.3 \\
Less than 4 years of schooling & 11.8 & 10.9 \\
1st cycle of basic schooling (4th year) & 26.0 & 18.7 \\
2nd cycle of basic schooling (6th year) & 47.4 & 42.8 \\
Primary education (9th year) & 12.7 & 17.5 \\
Secondary education (12th year) & 0.9 & 1.5 \\
3-year bachelor's degree & 0.5 & 1.3 \\
5-year bachelor's degree & 10.8 & 10.6 \\
Average years of schooling & & \\
Age & 43.0 & 26.1 \\
<21 & 42.4 & 47.8 \\
21-25 & 14.6 & 26.1 \\
>25 & & \\
Training program & 19.9 & 32.2 \\
Tourism & 11.3 \\
Accounting, Business \& Administration & 3.3 & 21.4 \\
Agricultural Production \& Food Industry & 8.3 & 7.7 \\
Environment \& Urbanism & 15.4 & 0.6 \\
Civil Construction & 12.2 & 1.3 \\
Electronics \& Energy & 7.2 & 0.2 \\
Applied Computer Sciences & 16.1 & 4.8 \\
Others & & 31.8 \\
Training duration (hours) & 16.6 & 25.7 \\
300-1199 & 50.2 & 37.9 \\
1200-2399 & 10.2 & 12.2 \\
2400-3599 & 23.1 & 24.2 \\
Z3600 & & \\
\hline
\end{tabular}

miscellaneous category 'Others' accounts for $16.1 \%$ and $31.8 \%$ of the courses in the male and female subsamples, respectively. ${ }^{3}$

In the literature, the research on incidence, extent and impacts of training is biased toward participation versus non-participation in training, whereas corresponding results for the role of the training intensity are mostly lacking. Interestingly, our dataset includes information on the duration of the program. As Table 1 shows, the duration is quite evenly distributed. Although between 1200 and $2399 \mathrm{~h}$ is the most frequent duration $(50.2 \%$ and $37.9 \%$ for males and females, respectively), the proportion of courses with very long duration (3600 h or more) is remarkably large $(23.1 \%$ males and $24.2 \%$ females).

\section{The transition from training to work}

Using raw statistics, we can outline some interesting patterns in the from-training-towork transition in Madeira. In Table 2, we report the labor status of training participants at different horizons. Two things are worth noting. First, most training recipients obtain a job immediately after training. One month after completion, $74.4 \%$ of men and $69.4 \%$ of women work as wage earners, and an additional $3.8 \%$ and $1.0 \%$ are self-

\footnotetext{
3 This category includes all courses that account for less than $3 \%$ of the total sample. It includes Social Service, Insurance Techniques, Clothing Industry, Information \& Communication, Furniture Industry, Beauty Care, Training for Trainers, Vehicle Mechanics and Nursery.
} 
Table 2: Labor status after the completion of the program (\%)

\begin{tabular}{|c|c|c|c|c|c|c|}
\hline \multirow[b]{2}{*}{ Status } & \multicolumn{2}{|c|}{ After 1 month } & \multicolumn{2}{|c|}{ After 1 year } & \multicolumn{2}{|c|}{ After 2 years } \\
\hline & Men & Women & Men & Women & Men & Women \\
\hline Wage earner & 74.4 & 69.4 & 79.3 & 80.9 & 80.1 & 72.9 \\
\hline Self-employed & 3.8 & 1.0 & 4.6 & 1.3 & 6.0 & 1.7 \\
\hline Family job (unpaid) & 2.5 & 1.0 & 1.6 & 0.6 & 0.3 & 0.3 \\
\hline Student & 4.6 & 3.4 & 5.4 & 3.9 & 6.0 & 4.8 \\
\hline Military service & 1.6 & 0.2 & 2.6 & 0.2 & 2.0 & 0 \\
\hline Unemployed & 12.7 & 24.2 & 5.9 & 12.3 & 5.4 & 19.1 \\
\hline Others & 0.4 & 0.9 & 0.5 & 0.9 & 0.3 & 1.1 \\
\hline
\end{tabular}

employed. These figures rise further when we consider the 2-year period $(80.1 \%$ and $72.9 \%$, and $6.0 \%$ and $1.7 \%$, respectively). Individuals who enter in a family job or the military service or decide to keep on studying account for a very small fraction of the sample.

Second, the evolution of the unemployment rate largely differs between men and women. Among men, unemployment decreases from an initial $12.7 \%$ to $5.9 \%$ in the first year and to $5.4 \%$ after 2 years. The evolution of this figure (parallel to an increasing proportion of wage earners) suggests a progressive integration in the labor market. ${ }^{4}$ Among women, in turn, the unemployment rate is as high as $24.2 \%$ after the first month, declines to $12.3 \%$ after 1 year and then surges up to $19.1 \%$ by the second year. Overall, these figures suggest that women not only face more difficulties in finding a job but also enter jobs that are less stable as well.

\section{Determinants of employment}

\section{The model}

In this section, we model the probability of being employed at different dates as a function of the individual characteristics and the type of the vocational program. We consider as employed those individuals who are self-employed as well as those who are wage earners. We do not consider as employed those who work for a family member and do not receive a salary. These workers, together with students and people in the military service, are dropped from the sample. ${ }^{5}$

We use a logit model in which the employment status of individual $i \quad\left(E_{i}=1\right.$ employed, $E_{i}=0$ unemployed) depends on a latent variable $E^{*}$, such that

$$
E_{i}= \begin{cases}1 & \text { if } E_{i}^{*} \geq 0 \\ 0 & \text { if } E_{i}^{*}<0\end{cases}
$$

We model the latent variable as

$$
E_{i}^{*}=\sum_{\mathrm{k}=1}^{\mathrm{K}} \beta_{k} H_{k i}+u_{i}
$$

where $H$ is a vector of individual characteristics including age, gender, educational background, and the content and duration (in hundreds of hours) of the vocational

\footnotetext{
${ }^{4}$ The regional unemployment rate has been stable and around 6\% during the last few years (http:/ / estatistica.gov-madeira.pt).

${ }^{5}$ This exclusion restriction affects $7.2 \%, 7.9 \%$, and $7.2 \%$ of the workers one month, one year, and two years after completion, respectively.
} 
program. Due to the small number of women in our sample (716 obs.), we do not run a separate regression for men and women. By including a gender dummy, we implicitly assume that the impact of the covariates on the dependent variable is the same for both genders. Finally, as we are using pooled data from 2000 to 2005, we also include a set of dummies to account for year-fixed effects. In each date, the probability of employment for individual $i$ is given by

$$
\operatorname{Prob}\left[E_{i}=1\right]=\frac{e^{\sum_{k=1}^{K} \beta_{k} H_{k i}}}{1+e^{\sum_{k=1}^{K} \beta_{k} H_{k i}}}
$$

We cannot conclude the description of the estimating model without noting that the information contained in the SI presents two limitations that condition our econometric strategy. First, the survey does not provide information on the dates at which the contracts are offered. Ideally, we would like to observe the timing of the event 'obtaining a job' and the number of job offers that the individuals receive over different horizons. Such information would capture more accurately the employment opportunities of training participants and would allow us to estimate the hazard function that governs the duration of unemployment, as in Holm (2002) and Hujer et al. (2006). In turn, with the information at hand, our analysis will be confined to estimating a set of logit models in which the dependent variable is the employment status at different dates. ${ }^{6}$

Second, the SI is confined to individuals that have completed a vocational program in Madeira Island and, thus, it does not report information on other population groups. This limitation does not allow us to compare the employment opportunities of those who participated (treated group) and those who never participated (control group) in a training program. However, the subjective questions included in the SI will allow us to provide an assessment on this issue.

\section{Empirical results}

In Table 3, we present the odds ratios of the estimated model. For the reference worker, they represent the factor by which the probability of employment increases for a marginal increase in a continuous variable and for a discrete change for dummy variables. We take, as the reference individual, a man, with less than primary education, aged below 21, who completed a course in the miscellaneous category 'Others'. First, we discuss the results found for all the variables included in the regression, then we turn to the findings on the relationship between training program and employment.

Schooling plays a crucial role in the access to a job. This effect, however, is only visible when we consider the longest time span. During the first month, the more educated do not show better results than the less educated. The only significant effect is due to primary education: relative to the remaining groups (secondary and tertiary as well as the reference group, less than primary education), individuals with the primary level face a lower probability of being employed. Interestingly, this situation reverts when we consider the 2-year period. In this scenario, the educated show a much higher probability of employment. Specifically, we find that having primary, secondary and tertiary education increases the predicted probability by a factor of 1.75, 7.22 and

\footnotetext{
${ }^{6}$ We also experimented with a two-stage model in which the employment status at date $t$ was estimated in a first stage and, in a second stage, the predicted probabilities were included as an additional regressor in the equation for employment at date $t+j$. The results (available upon request) are qualitatively similar to those obtained with independent logits. Specifically, we found that most variables that are significant in the longer run are also significant when we control for employment in the previous period.
} 
Table 3: Determinants of employment

\begin{tabular}{|c|c|c|c|c|c|c|}
\hline & \multicolumn{2}{|c|}{ After 1 month } & \multicolumn{2}{|c|}{ After 1 year } & \multicolumn{2}{|c|}{ After 2 years } \\
\hline & Odds ratio & $z$-ratio & Odds ratio & $z$-ratio & Odds ratio & $z$-ratio \\
\hline Primary education & $0.785^{*}$ & -1.63 & 1.283 & 1.26 & $1.749^{* * *}$ & 3.08 \\
\hline Secondary education & 1.235 & 0.82 & $2.941^{* * *}$ & 2.88 & $7.222^{* * *}$ & 5.25 \\
\hline Tertiary education & 2.115 & 1.31 & 2.016 & 1.21 & $11.775^{* * *}$ & 3.23 \\
\hline $20<$ Age $\leq 25$ & 0.855 & -1.09 & 0.978 & -0.11 & 0.944 & -0.30 \\
\hline Age $>25$ & 0.865 & -0.85 & 0.714 & -1.58 & $0.618^{* *}$ & -2.41 \\
\hline Female & $0.443^{* * *}$ & -5.34 & $0.501^{* * *}$ & -3.35 & $0.279^{* * *}$ & -5.94 \\
\hline Tourism & 0.797 & -1.32 & 1.020 & 0.91 & $1.049 * *$ & 2.23 \\
\hline $\begin{array}{l}\text { Accounting, Business } \\
\text { \& Administration }\end{array}$ & 0.811 & -1.07 & $1.628^{*}$ & 1.67 & 1.219 & 0.74 \\
\hline $\begin{array}{l}\text { Agricultural } \\
\text { Production \& Food } \\
\text { Industry }\end{array}$ & $0.533^{* *}$ & -2.34 & 0.994 & -0.02 & $0.333^{* * *}$ & -3.69 \\
\hline $\begin{array}{l}\text { Environment \& } \\
\text { Urbanism }\end{array}$ & $0.400^{* * *}$ & -2.73 & 1.154 & 0.25 & 0.968 & -0.06 \\
\hline Civil Construction & $0.592^{*}$ & -1.75 & 0.734 & -0.81 & 0.945 & -0.14 \\
\hline Electronics \& Energy & 0.881 & -0.32 & 2.026 & 1.10 & $1.376^{* * *}$ & 2.60 \\
\hline $\begin{array}{l}\text { Applied Computer } \\
\text { Sciences }\end{array}$ & $0.600^{*}$ & -1.80 & 0.674 & -1.11 & 0.811 & -0.54 \\
\hline Duration & $1.035^{*}$ & 1.83 & 1.035 & 1.40 & $1.103^{* * *}$ & 4.00 \\
\hline Duration squared & $0.999^{* *}$ & -2.25 & 0.999 & -1.62 & $0.999^{* * *}$ & -3.84 \\
\hline Average probability & 0.800 & & 0.895 & & 0.853 & \\
\hline Pseudo r-squared & 0.044 & & 0.064 & & 0.206 & \\
\hline No. of observations & 1915 & & 1915 & & 1915 & \\
\hline
\end{tabular}

* significant at the $10 \%$ confidence level.

** significant at the $5 \%$ confidence level.

*** significant at the $1 \%$ confidence level.

11.78 , respectively. These estimates are highly increasing, thus pointing to an exponential effect of formal qualifications on the employment probability.

Using international data, Martins and Pereira (2004) showed that as measured by wages, the labor market reward to education is particularly large in Portugal. Our results show that as far as training recipients in Madeira are concerned, education also pays in terms of employability. This positive effect, however, applies only for the longer term, probably because the educated are more inclined to reject initial job offers and to extend the duration of the job search. There are at least three channels by which these incentives may operate. First, the high educated have higher reservation wages, and may optimally postpone entering employment in order to access high-level occupations. Second, having acquired skills and competencies through (costly) education, the educated have incentives to reject offers for jobs that are not commensurate with their qualifications. Third, more educated individuals are more likely to benefit from a safety net that allows them to remain unemployed for longer. There is consistent evidence that the educated tend to come from richer families. As a consequence, they can more easily finance unemployment spells and reduce the disutility from being unemployed. ${ }^{7}$ Moreover, educated individuals tend to receive larger amounts from income sources other than wages, such as capital income, transfers and bequests (Budría \& Díaz-Giménez, 2007).

\footnotetext{
7 See Asplund and Barth (2005) for international evidence on the connection between family characteristics (including income) and educational attainment.
} 
Age does not significantly affect the probability of employment during the first year. However, it exerts a negative effect when we consider the 2-year period. In this case, the odds ratio of the above- 25 age group shows that older individuals have a probability of employment that is only $61.8 \%$ that of younger individuals. A candidate explanation for this pattern is that older workers tend to enter jobs that are less stable or, alternatively, that they have a safety net that allows them to live without working.

We find that, irrespective of the time horizon considered, women are more prone to be unemployed after completing the training. Specifically, the probability for a woman of being employed in the first month is only $44.3 \%$ that of men, ceteris paribus. This figure rises to $50.1 \% 1$ year after but then falls to a remarkably low $27.9 \%$ by the second year. Being a woman, therefore, reduces the probability of employment at the end of the period by a factor of almost four.

Next, we turn to the role of the training program. As regards the content of the training, we detect important differences across areas. Considering the $10 \%$ confidence level as a threshold for significance and non-significance, we find that during the first month, individuals from Agricultural Production \& Food Industry, Environment \& Urbanism, Civil Construction and Applied Computer Sciences have a significantly lower probability of finding a job, relative to an individual from the reference program. One year after completion, the effect of Accounting, Business \& Administration turns from non-significant to positive and significant, while differences between the remaining programs are not relevant. Finally, 2 years after the program, we find that Tourism, as well as Electronics \& Energy, show positive and significant effects. Individuals from these areas have a probability of being employed, that is, respectively, $4.9 \%$ and $37.6 \%$ higher than the probability of the reference individual.

The training duration is another relevant variable. The results in Table 3 are in line with the intuition that investing in human capital for longer periods must yield larger gains. The coefficients on duration and duration squared show that the number of hours exerts a positive though decreasing effect on the employment probability. This effect is particularly large when we consider the 2-year period. In this case, for instance, a 100 increase in the number of hours raises the predicted probability by about $10 \%$.

Finally, we note that the goodness of fit of the estimating model rises as we consider a longer time span. The low $R^{2}$ in the first two models (0.044 and 0.064 , respectively) suggests that employment during the first year depends largely on unobservable factors. Notwithstanding this, the two models are jointly significant for employment determination. Interestingly, the $R^{2}$ in the last model (0.206) is relatively high for a categorical dependent variable, indicating that our explanatory variables are indeed relevant for employment determination in the longer run.

\section{The participants' self-assessment}

\section{The model}

The SI asks individuals to self-evaluate several aspects of the training program. The key questions are:

- (Q1) Has the vocational training program helped you to obtain your current job?

- (Q2) Was the vocational training program related to your current job?

- (Q3) Has the vocational training program improved your productivity at your current job?

where the candidate answers range from ' 1 ' (completely disagree) to ' 4 ' (completely agree). We use Q1, Q2 and Q3 to examine the extent to which training contributes to employment, provides skills that later on are used in the job and raises productivity. We also examine how these effects differ between individuals with different observable characteristics and between training programs. As a limitation, the above questions are answered only by those individuals who were employed at the time of the survey 
(2 years after the training). Thus, we cannot evaluate the training activities for shorter time spans. ${ }^{8}$

Admittedly, Q2 cannot be regarded as a direct question on the skills acquired through training. However, it can be interpreted as an assessment of the quality of the match between the content of the training and the skills required in the job, as individuals whose training does not relate to the job can hardly have acquired the necessary skills and competencies in the training. This question, moreover, closely resembles other survey questions that are typical in the emerging literature on skills and educational mismatches. ${ }^{9}$

As our dependent variable is a ranked categorical variable, we adopt an ordered logit model in which the answer to a particular question (an ordinal variable $I$ that takes values from 1 to 4 ) depends on a latent variable $I^{*}$ that is not measured. This latent variable is continuous and has several threshold points that determine the observed value of $I$. In our particular case,

$$
I_{i}= \begin{cases}1 & \text { if } I_{i}^{*} \leq \delta_{1} \\ 2 & \text { if } \delta_{1} \leq I_{i}^{*} \leq \delta_{2} \\ 3 & \text { if } \delta_{2} \leq I_{i}^{*} \leq \delta_{3} \\ 4 & \text { if } I_{i}^{*} \geq \delta_{3}\end{cases}
$$

Likewise, in the simple logit specification, we model variable $I^{*}$ as a function of our vector of explanatory variables

$$
I_{i}^{*}=\sum_{\mathrm{k}=1}^{\mathrm{K}+1} \beta_{k} H_{k i}+e_{i}
$$

where $H$ now includes an additional covariate: the type of contract held by the individual. This will allow us to explore whether or not the contribution of training to employment takes place through temporary or permanent contracts, and whether or not the type of contract fosters the utilization of skills acquired in the training.

\section{Results from the participants' self-assessment}

In Table 4, we report the estimates of the three ordered logits. The coefficients represent the marginal effect of a given covariate on the mean of the dependent variable. The omitted category is a male worker, aged below 21, with less than primary education, with a temporary contract and with training in the miscellaneous category 'Others'.

Probably, the most remarkable finding is the complementarity between schooling and training. In the previous section, we found that individuals with formal qualifications are more prone to be employed after exit from training. The results in the first column of Table 4 show that this performance can be partly attributed to training itself.

\footnotetext{
8 The pattern of early career histories is diverse among young people, and some individuals may switch jobs frequently during the first months of job search. In our analysis, we have pooled together individuals who were in their first job after training (86.3\% of the sample) and individuals who had had two or more jobs (13.7\%). Admittedly, these two groups of workers may be inclined to respond differently, as the contribution of past training activities to the current job may differ depending on the number of jobs that the individual has had. Thus, for example, training may facilitate access to a first job that may act as a stepping-stone to other jobs for which the skills acquired in the training are no longer needed. Still, in results not reported here, we found that restricting the sample to individuals in their first job does not significantly change the results.

9 See, for instance, Alba-Ramírez and Blázquez (2002), Budría and Moro-Egido (2008) and Wasmer et al. (2007). Here, the key questions are 'To what extent is your formal training or education related to your current job?' and 'Have you had formal training or education that has given you skills needed for your present type of work?'.
} 
Having secondary or tertiary education raises the score on employability significantly, by about 0.40 points, indicating that workers with these qualifications find the training particularly useful to obtain a job. Moreover, a glance to the second and third columns of Table 4 shows that individuals with a higher education level are more inclined to believe that the training activity is related to their current job, and that they are more productive due to the training program. The effects of having secondary and tertiary education on these scores range from 0.33 to 0.61 , and are statistically significant at the $1 \%$ confidence level. In contrast, individuals with primary education or less find the vocational training less effective in every dimension. Overall, the results indicate that, relative to the educated, the low educated get a worse match between the skills acquired through training and the skills needed to either obtain or perform a job.

The results for the remaining variables are as follows. Age is an additional determinant of the contribution of training to employment. Specifically, we find that relative to younger individuals, those aged over 25 find the training program less effective when it comes to obtaining a job. The estimated coefficient, -0.221 , is statistically significant but becomes non-significant when we switch to columns two and three. Regarding job-related skills and productivity, therefore, we do not detect significant differences across age groups.

In the previous section, we showed that relative to men, women are more prone to be unemployed after the training. As is apparent in Table 4, this employment gap is not driven by a differential effect of training on the employment opportunities of both genders. In other words, there is no evidence that upon the employment dimension, training is more effective among men. Regarding the remaining dimensions, we find that training is similarly related to the job in both genders. Still, the impact of training on productivity is higher among women (0.083), a result that can be interpreted as some evidence that women tend to obtain a better match between the job requirements and the skills acquired through training.

In the previous section, we found that Tourism was associated with a higher probability of employment in the longer term. The results in Table 4 indicate that this is also the perception of respondents: those who completed a program in Tourism feel that their investment significantly contributed to obtain their current job. Moreover, employment does not come at the expense of a bad job match. Participants in Tourism report that the program was related to the job or, to put it differently, that they access jobs that are related to the skills acquired in the training. Still, this effect is significant only at the $10 \%$ confidence level. The last column of Table 4 suggests that participants in Tourism programs are inclined to believe that the training activity raised their productivity, but the effect fails to be statistically significant. Regarding the remaining courses, we find that Applied Computer Sciences shows the worst results. Individuals from this area find the training less valuable in every dimension, and the estimates are significant at the $1 \%$ confidence level. We also find that individuals from Accounting, Business \& Administration and Agricultural Production \& Food Industry tend to find jobs that are less related to the vocational program. However, this does not translate into lower productivity levels.

The duration of the training activity is positively related to the probability of finding a job, the quality of the match between the training content and the job, and productivity. Specifically, an increase of $100 \mathrm{~h}$ in the duration of the training raises the score on these dimensions by between 0.03 and 0.04 points. This result matches $a$ priori expectations, as individuals from longer training schemes are more likely to have acquired skills and competencies that later on allow them to access certain occupations and be more productive in their jobs.

As an additional finding, we note that the type of contract is a strong determinant of the perceived effectiveness of training. According to the results, training attendees benefit from additional opportunities of being offered a permanent contract (0.231). This finding suggests that in the regional labor market, employers may be using training as a screening device to hire workers permanently. It may well be that high ability and more committed individuals undertake training activities to signal their higher quality to the regional employers who, in turn, use the training experience as a 


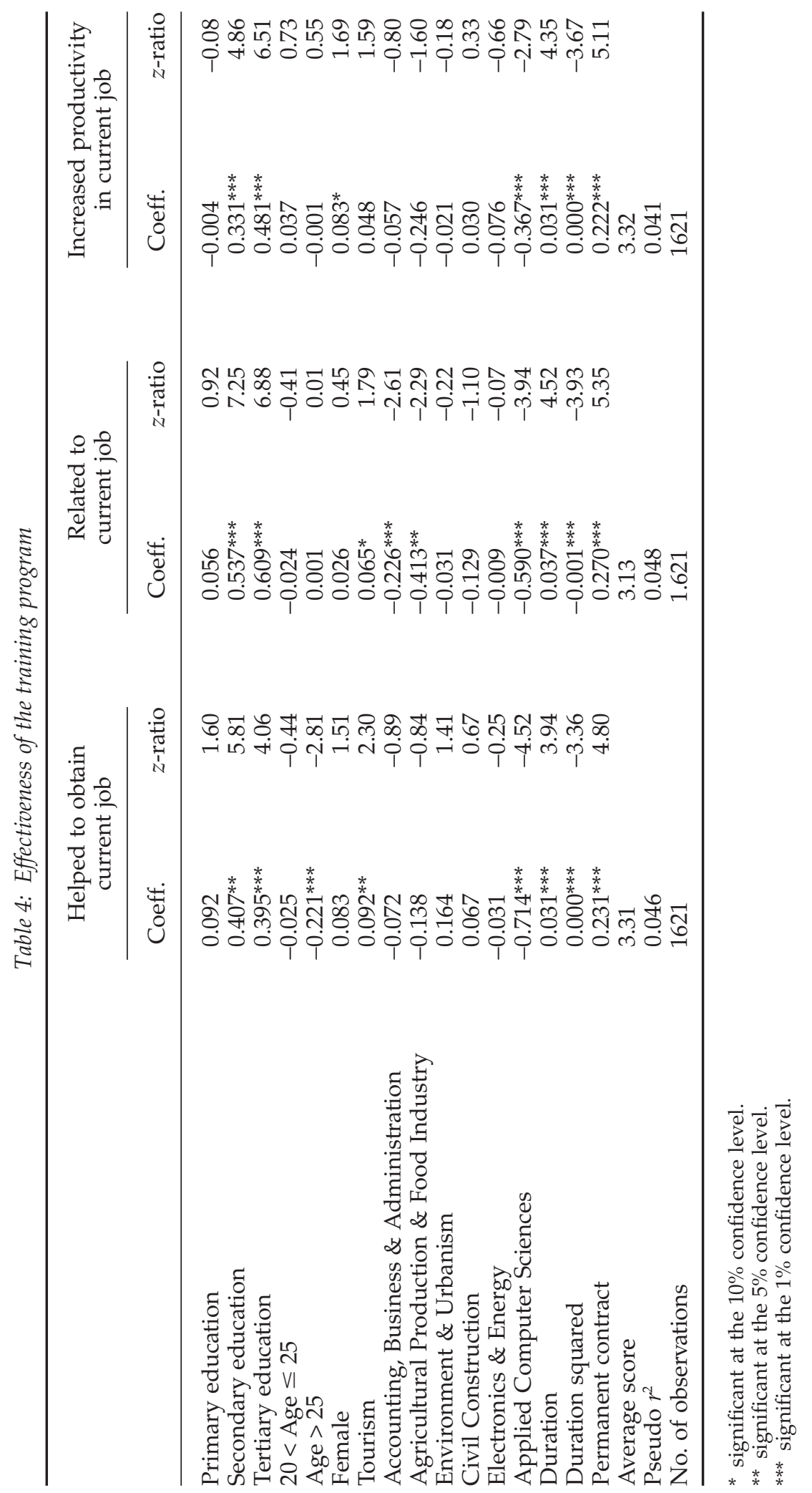


Table 5: Distribution of responses (\%)

\begin{tabular}{lcccc}
\hline & $\begin{array}{c}\text { 1-Completely } \\
\text { Disagree }\end{array}$ & 2- Disagree & 3- Agree & $\begin{array}{c}4 \text { - Completely } \\
\text { agree }\end{array}$ \\
\hline $\begin{array}{l}\text { Helped to obtain } \\
\quad \text { current job }\end{array}$ & 10.9 & 6.2 & 23.1 & 59.8 \\
$\begin{array}{l}\text { Related to current job } \\
\text { Increased productivity }\end{array}$ & 12.7 & 8.9 & 30.5 & 48.0 \\
$\quad$ in current job & 6.9 & 7.7 & 31.5 & 53.9 \\
\hline
\end{tabular}

basis for the decision to offer a permanent contract. Still, the mechanism operating here is not a pure signal effect. There is also a human capital effect, as those with a permanent contract obtain jobs that are more related to the vocational course $(0.270)$ and, probably as a consequence, end up being more productive in their jobs $(0.222)$.

A final comment regards the overall evaluation of the training program made by training participants. Despite significant differences across groups of workers, the general evaluation is fairly good. This can be seen in the bottom part of Table 4, where we report the average response in the 1-4 scale provided by the trainees (under the heading 'Average score'). The three dimensions are scored high on average (3.31, 3.13 and 3.32, respectively), indicating that training completers more than agree that training improves the chances of having a job, is related to future jobs and raises one's productivity. In Table 5, we provide the precise distribution of the responses. As much as $59.8 \%$ of the sample workers 'completely agree' that training was useful to obtain the job, whereas an additional $23.1 \%$ 'agree'. In contrast, only $10.9 \%$ of the total sample 'completely disagree' with this statement. Similarly, $78.5 \%$ and $85.4 \%$ of the respondents 'agree' or 'completely agree' with the second and third evaluation questions, respectively. Again, the proportion of individuals who less than agree along these two dimensions is relatively low $\left(21.6 \%\right.$ and $14.6 \%$, respectively). ${ }^{10}$

In the previous section, we noted that the SI cannot be used to estimate the treatment effect of being trained (relative to not being trained) on the employment probability. The subjective questions analysed in this section allow us to shed light on this issue: according to the workers' perceptions, training activities significantly contribute to obtain a job.

\section{Discussion}

\section{Human capital theory}

According to Human Capital Theory (Becker, 1964), individuals may raise their productivity by investing in education. However, although the positive effects of formal schooling on earnings, employment and productivity have been widely documented in the literature, the labor market implications of training and vocational education are less clear cut. There is evidence pointing to beneficial effects of training activities on unemployment duration, productivity and wages (Conti, 2005; Richardson \& van den Berg, 2001; Van Reenan et al., 2006). Still, evaluation studies of public training programs in OECD countries often report that adult and vocational training have little directly

\footnotetext{
${ }_{10}$ When inquired about past training activities, working individuals may be inclined to overstate the contribution of the training to their current job for the sake of consistency. Still, there is evidence to suggest that individuals are well aware of the true labor market effects of training: the subjective evaluation of the employability dimension reported in the first column of Table 4 is fairly consistent with the objective employment probabilities reported in the last column of Table 3 . Specifically, we find that more educated, younger individuals with training in Tourism or from long duration programs are (objectively) more likely to be employed two years after the training, and this is exactly their (subjective) perception.
} 
measurable labor market effects, failing to attract earnings returns and new employment opportunities (Fitzenberger \& Prey, 2000; Machin \& Vignoles, 2005; Martin \& Grubb, 2001).

The results in this paper provide further support to the Human Capital Theory. We showed that vocational training may importantly improve the labor market prospects of individuals, providing job-related skills, enhancing productivity and bringing new employment opportunities. The divergence with previous research may be due to at least three factors. First, there is evidence to suggest that educational differences should be explicitly taken into account. The results reported in the OECD's (2004) Employment Outlook provide only limited evidence at the international level and no evidence in the Portuguese case that training participation decreases the probability of unemployment (p. 196). This evidence, however, is obtained aggregating individuals across education levels or, to put it differently, obscured by heterogeneous effects. Our results indicate that the contribution of training to productivity and employment may not be an independent effect, but the outcome of a positive interaction between schooling and training. Specifically, the observation that educated individuals benefit to a larger extent from training activities suggests that vocational training acts by fostering the effects of formal schooling rather than by replacing limited or outdated education. Once educational differences are explicitly taken into account, the estimated effects can be remarkably large among specific groups. This result warns training practitioners and researchers in the field that the interaction between schooling and training should be explicitly taken into account for the design of effective training schemes.

Second, in some countries, the proliferation of vocational qualifications and schools may have lowered the average quality of training attendees and weakened the signal of what students who go through a vocational program learn. To some degree, this mechanism may be operating in those countries where vocational schemes fail to be effective. In Madeira Island, in turn, the public provision of vocational training is highly centralized at the regional level, which has resulted in a relatively small number of vocational paths, a clearer mapping between the regional labor market needs and vocational courses, and a wider recognition by regional employers. Screening and signaling effects are more likely to operate in this particular context, providing training completers with useful labor market credentials.

Third, in Portugal, the returns to education are remarkably large, partly due to the low educational attainment and training participation of the labor force. ${ }^{11}$ The fact that vocational training completers benefit from better opportunities in Madeira Island than in other countries is consistent with this pattern.

In theoretical discussions about the relation between education and training, the question of complementarity or substitutability between these two different forms of human capital is frequently raised. If training is more effective among the educated, then an expansion in training provision may deteriorate the labor market position of already disadvantaged individuals. On the other hand, if training acts as a substitute for formal schooling, existing differences in labor market performance and productivity between educated and uneducated workers could be ameliorated. The results in this paper give support to the complementarity hypothesis, thus warning that equality of training provision may result in further labor market inequalities. Lynch (1992) for the US, Blundell et al. (1999) for the UK and Brunello (2004) for Europe as a whole report similar findings.

The complementarity between training and education can be explained by at least two factors. First, schooling plays a particularly important role during the screening process of recent school-leavers, who unlike more experienced workers normally do not possess productivity signals other than their education. Therefore, we expect that those with a higher level of schooling tend to benefit from additional opportunities

\footnotetext{
${ }^{11}$ In Portugal, only $27.6 \%$ of the adult population (25-64 years old) has completed upper secondary education, while in Europe as a whole (EU-25) this proportion rises to $69.7 \%$. Similarly, training participation in Portugal is 3.8\%, against 10.1\% in EU-25 (Eurostat, 2007).
} 
after completion of the training. Second, it has been documented that mental ability and motivation are strong determinants of the extent of knowledge acquisition among training participants, and that these factors are closely related to the individual's educational attainment (Cannon-Bowers et al., 1995; Colquitt et al., 2000). It is likely, therefore, that the higher capacity of knowledge acquisition of the educated leads them to increased productivity and more occupational opportunities.

\section{The role of education}

The connection between education and employment opportunities found in the data is not new in the literature. Still, our results provide an assessment on the magnitude of these effects among training completers and, given the lack of empirical research on the subject, help contextualize Portugal and Madeira in the global arena. At the international level, there exist large variations between countries regarding the impact of education on unemployment rates. The latest OECD's report Education at a Glance (OECD, 2008) provides important insights on this issue. Among OECD countries, an upper secondary education is typically considered the minimum for a satisfactory competitive position in the labor market. Depending on a country's industry composition and level of economic development, the gap between the unemployment rate of workers with and without upper secondary education is found to vary largely across countries, ranging from 34\% in the Slovak Republic and 9\% in Germany to $0.5 \%$ in Portugal and a negative differential in Turkey $(-0.7 \%)$ and Greece $(-1.5 \%)$. Similarly, the employment gap between individuals with upper secondary and tertiary education shows substantial variation. Still, the average gap (5\% in OECD countries and $1.7 \%$ in Portugal) indicates that higher education pays in terms of employability (OECD, 2008, table A8.5a, pp. 159-60).

Turning to our estimates, we find that the impact of education on the employment probability is remarkably large among training recipients in Madeira. Specifically, we find that having primary, secondary and tertiary education increases the probability of employment by a factor of 1.75, 7.22 and 11.78, respectively. These figures contrast sharply with the OECD average figures, according to which individuals with tertiary education are only 2.6 times more likely to be employed than individuals with less than upper secondary education and 1.5 times more likely than individuals with upper secondary education.

\section{Selection into training}

It may be argued that the close connection between education and employment opportunities documented in the paper may be driven by the selection of educated people into the most effective training programs. If educated workers are in some way more likely to self-select or be selected into those training schemes that later on are more rewarded in the labor market, then their higher employability would be due to the training program rather than to education itself. To isolate the education effect from the selection-into-training-effect, we conducted separate regressions by training areas. ${ }^{12}$ The results are reported in Table 6 . The estimates correspond to the coefficient of a dummy variable that takes the value 1 if the individual has secondary or tertiary education, zero otherwise. ${ }^{13}$

\footnotetext{
12 Our first strategy was to estimate a two-stage model in which a training participation equation was first calculated and, in a second stage, our benchmark equations were re-estimated using the predictions obtained in the first stage. This would have allowed us to remove from the education effect those factors that simultaneously determine employment opportunities and the probability of entering a particular training program. However, this road was not open to us, due to the large number of training areas, the lack of valid instruments (i.e. variables correlated with the training area and uncorrelated with the employment status) and the few observations in each training group.

${ }_{13}$ We do not differentiate between secondary and tertiary education due to small cell size within the various training groups.
} 


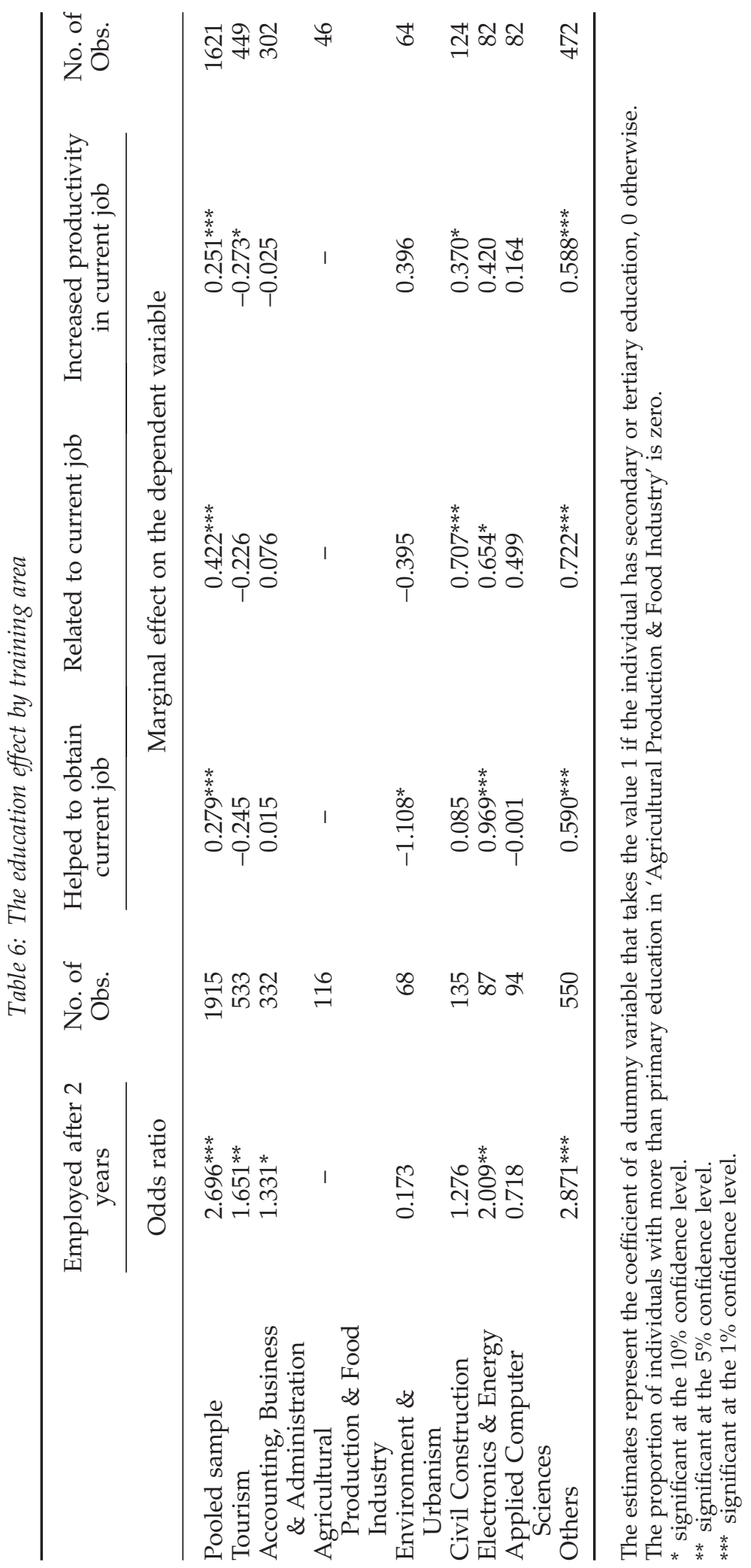


The first column reports the effect of having more than primary education on the probability of being employed 2 years after the program. The rows show how this effect varies when the estimating sample is restricted to a particular training group. Due to the small number of observations within the groups, the estimated coefficients tend to be less statistically significant. Notwithstanding this, a clear pattern emerges: in most training programs (Tourism, Accounting, Business \& Administration, Civil Construction, Electronics \& Energy and Other programs), educated individuals benefit from better employment opportunities. Only in two areas (Environment \& Urbanism and Applied Computer Sciences) is education associated with a lower probability of employment. In these cases, however, the estimated effect fails to be statistically significant.

Turning to the subjective questions, we detect some differences across groups. The education effect is particularly large among individuals from Electronics \& Energy and Other areas when it comes to either obtaining a job (0.97 and 0.59 , respectively) or obtaining a job related to the training (0.65 and 0.72). Similarly, having formal qualifications is particularly relevant for the acquisition of job-related skills and productivity among workers from Civil Construction. Only in two areas, Tourism and Environment \& Urbanism, does education appear to negatively affect the labor market outcome.

\title{
Conclusions
}

One of the major concerns for the Portuguese economy over the last few years has been to promote productivity, economic competitiveness and occupational integration. For that purpose, the development of new vocational training schemes was regarded as crucial by national and international economic authorities. In an earlier report, the OECD indicated that reforms in the Portuguese labor market

\begin{abstract}
should be accompanied by a stronger emphasis on vocational training, to ease the school-to-work transition. New rules permitting employment of unqualified youths on condition that training is provided by the employer may help, but it would be better if the schools themselves were better able to provide school-leavers with qualifications useful to employers [ ... ]. The government's aim to provide employment-related training to all youths that are registered in employment centers and a renewed emphasis on life-long training are welcome (OECD, 2003).
\end{abstract}

Understanding and improving the process of knowledge transfer and labor market integration has become, thus, a primary concern for training practitioners, governments and researchers. In this paper, we contributed toward a better perception of this process by analysing the transition to the labor market of participants in vocational training programs. We explored how the employment status after the completion of the program depends on relevant variables, including age, gender, education, and the content and duration of the training. We found that educated, young and male individuals are more prone to be employed after exit from training, particularly in the longer run. Moreover, we found that training with long duration and training in specific areas raise the probability of employment.

The results were complemented with the individuals' self-assessment regarding the effectiveness of the course along three dimensions: employment, job-related skills and productivity. The average score in every dimension was fairly high, indicating that the beneficial effects of training are widely recognized among participants. We found that more educated individuals find the training program more effective in every dimension. This result lead us to conclude that training significantly contributes to the faster transition to employment experienced by this group of workers. We also reported that women tend to benefit more from the productivity gains acquired through training, and that the perceived effectiveness of training depends on the content and duration of the program.

Our results have several implications for public policy. First, they warn policy makers that vocational training is far from being remedial, at least in Madeira Island. Current vocational training is not a substitute for formal schooling. The strong complementarity between schooling and training found in the data suggests that training schemes 
oriented to the less educated may be less effective than previously thought. In an earlier work (Budría \& Pereira, 2007), we reported that in Portugal, less-educated workers earned a higher wage premium from training activities, and concluded that training had a remedial nature. The results in this paper suggest that this is not the case when it comes to employment opportunities, job-related skills and productivity. If policy makers are concerned with promoting employment among the less favored in the labor market, the existing training schemes should be redesigned in order to amend the educational and skills limitations that some training participants exhibit from the start. In this respect, training aimed to acquire general skills and competencies rather than specific knowledge may be of particular importance.

Second, educational and skills mismatches are a hot topic in contemporary labor markets. A significant proportion of the labor force in western economies works in jobs that are not commensurate with the skills acquired through their education and training (Groot \& van den Brink, 2000). These workers end up earning less, being less productive and reporting lower levels of job satisfaction (Hartog, 2000; McGuinness, 2006). In this paper, we showed that training provides individuals with skills that later on are required to either obtain or perform a job. This result indicates that policies aimed to encourage and increase the overall participation in training may importantly reduce the extent of skills mismatches by aligning the workers' skills with the realities and needs of the labor market. Still, the quality of the match between the requirements of the job and the skills acquired through training importantly differs across groups of individuals. Here, again, the emphasis should be placed on the less educated, among which the quality of the match was found to be lower. Clearly, future research should examine the generalizability of our results to other regions and training schemes.

Third, there is evidence to suggest that training in Tourism, an activity that is core for Madeira Island, improves the labor market prospects of individuals. This was assessed using an objective measure of employability (the labor market status 2 years after the completion of the program) and a subjective measure (the individuals' selfassessment). This finding adds to the regional debate of how and to what extent should private and state interventions be oriented to develop workforce skills that are necessary for the successful development of the region. The evidence presented here suggests that training in the area of Tourism is particularly beneficial. It may well be that participants in Tourism programs contribute to sustainable and well-managed tourism by raising the general level of knowledge in the sector, inculcate appropriate environmental and organizational attitudes and values, and provide the tools to apply these to specific jobs in the regional labor market. The fact that individuals with training in the field are more prone to be employed seems to be consistent with this view.

The next natural step of this research is to examine the labor market consequences of participation versus non-participation in training activities, and to expand the set of self-assessed questions provided by training participants. There is evidence suggesting that motivation to learn, trainees' expectation fulfillment and perceived training difficulty may be relevant factors explaining knowledge acquisition (Colquitt et al., 2000; Rowold, 2007). Due to data limitations, these dimensions were not explored in the present study. Also, the acquisition and development of new training data containing detailed information on the labor market status of participants and non-participants in vocational training would be valuable to shed light on important questions, such as the individual returns to training and the effects of training participation on job security and employment rates. Similarly, longitudinal data containing the timing of the investment in which the employment situation at different dates is the focus of the analysis would be desirable, insofar as the temporal ordering of cause and effect could be established. These efforts are a compelling task for future research.

\section{References}

Alba-Ramírez, A. and Blázquez, M. (2002), 'Types of job match, overeducation, and labour mobility in Spain', in F. Büchel, A. de Grip and A. Meitens (eds), Overeducation in Europe: Current Issues in Theory and Policy (Cheltenham: Edward Elgar Publishing), pp. 65-90. 
Asplund, R. and Barth, E. (2005), Education and Wage Inequality in Europe: A Literature Review (Helsinki: The Research Institute of the Finnish Economy).

Bartel, A. P. (1995), 'Training, wage growth, and job performance: evidence from a company database', Journal of Labour Economics, 13, 401-25.

Becker, G. (1964), Human Capital: A Theoretical and Empirical Analysis with Special Reference to Education (New York: Columbia University Press).

Bishop, J. (1994), 'The impact of previous training on productivity and wages', in L. Lynch (ed.), Training and the Private Sector: International Comparisons (Chicago, IL: University of Chicago Press), pp. 161-200.

Black, S. and Lynch, L. (1996), 'Human-capital investments and productivity', American Economic Review, 86, 263-7.

Blundell, R., Dearden, L. and Sianesi, B. (1999), 'Human capital investment: the returns from education and training to the individual, the firm and the economy', Fiscal Studies, 20, 1, 1-23.

Bound, J., Jaeger, D. and Baker, R. (1995), 'Problems with instrumental variables estimation when the correlation between the instruments and the endogenous explanatory variable is weak', Journal of the American Statistical Association, 90, 443-50.

Brunello, G. (2004), 'On the complementarity between education and training in Europe', in D. Checchi and C. Lucifora (eds), Education, Training and Labour Market Policies in Europe (London: Palgrave Macmillan), pp. 188-210.

Budría, S. and Díaz-Giménez, J. (2007), 'Economic inequality in Spain: the European Union household panel dataset', Spanish Economic Review, 9, 1, 1-38.

Budría, S. and Moro-Egido, A. (2008), 'Education, educational mismatch, and wage inequality: evidence for Spain', Economics of Education Review, 27, 3, 332-41.

Budría, S. and Pereira, P. T. (2007), 'The wage effects of training in Portugal: differences across skill groups, genders, sectors, and training types', Applied Economics, 39, 787-807.

Cannon-Bowers, J. A., Salas, E., Tannenbaum, S. and Mathieu, J. E. (1995), 'Toward theoretically based principles of training effectiveness: a model and initial empirical investigation', Military Psychology, 7, 141-64.

CNCLSTP (Cabinet of the National Coordinator of the Lisbon Strategy and Technological Plan) (2006), The Portuguese Technological Plan (Lisbon: Portuguese Ministry of Science and Education).

Colquitt, J. A., LePine, J. A. and Noe, R. A. (2000), 'Toward an integrative theory of training motivation: a meta-analytic path analysis of 20 years of research', Journal of Applied Psychology, 85, 678-707.

Conti, G. (2005), 'Training, productivity and wages in Italy', Labour Economics, 12, 4, 557-76.

Eurostat (2007), 'Structural indicators, Luxembourg'. Available at: http://epp.eurostat. ec.europa.eu (accessed 5 October 2007).

Fitzenberger, B. and Prey, H. (2000), 'Evaluating public sector sponsored training in East Germany', Oxford Economic Papers, 52, 3, 497-520.

Fitzenberger, B. and Völterb, R. (2007), 'Long-run effects of training programs for the unemployed in East Germany', Labour Economics, 14, 4, 730-55.

Frey, B. and Stutzer, A. (2002), Happiness and Economics: How the Economy and Institutions Affect Human Well-Being (Princeton, NJ: Princeton University Press).

Groot, W. and van den Brink, H. (2000), 'Overeducation in the labour market: a meta-analysis', Economics of Education Review, 19, 149-58.

Hartog, J. (2000), 'Mismatch and earnings: where are we, where should we go', Economics of Education Review, 19, 131-47.

Hartog, J., Pereira, P. T. and Vieira, J. C. (2000), 'Vocational training and earnings in Portugal', Economia, 24, 1-24.

Holm, A. (2002), 'The effect of training on search durations: a random effects approach', Labour Economics, 9, 3, 433-50.

Hujer, R., Thomsen, S. L. and Zeiss, C. (2006), 'The effects of vocational training programmes on the duration of unemployment in Eastern Germany', Advances in Statistical Analysis, 90, 2, 299-321.

Jespersen, S. T., Munch, J. and Skipper, L. (2008), 'Costs and benefits of Danish active labour market programmes', Labour Economics, 15, 5, 859-84.

Kahneman, D., Diener, E. and Schwarz, N. (1999), Well-Being: The Foundations of Hedonic Psychology (New York: Russell Sage Foundation).

Lynch, L. (1992), 'Private sector training and its impact on the earnings of young workers', American Economic Review, 82, 1, 299-312.

Machin, S. J. and Vignoles, A. (eds) (2005), What's the Good of Education? The Economics of Education in the UK (Princeton, NJ: Princeton University Press). 
McGuinness, S. (2006), 'Overeducation in the labour market', Journal of Economic Surveys, 20, 3, 387-418.

Martin, J. P. and Grubb, D. (2001), 'What works and for whom: a review of OECD countries' experience with active labour market policies', Swedish Economic Policy Review, 8, 2, 9-56.

Martins, P. S. and Pereira, P. T. (2004), 'Does education reduce wage inequality? Quantile regressions evidence from 16 countries', Labour Economics, 11, 3, 355-71.

OECD (2003), Portugal - Assessment and Recommendations, OECD Economic Surveys, available at http://www.bportugal.pt/publish/other/ocde03e.htm (accessed 5 October 2007).

OECD (2004), Employment Outlook (Paris: OECD).

OECD (2005), Education at a Glance (Paris: OECD).

OECD (2006), Economic Survey of Portugal, 2006. OCDE Policy Briefs, Available at: http:// www.OCDE.org/dataOCDE/62/28/36497355.pdf (accessed 5 October 2007).

OECD (2008), Education at a Glance (Paris: OECD).

Pischke, J.-S. (2001), 'Continuous training in Germany', Journal of Population Economics, 14, 3, $523-48$.

Richardson, K. and van den Berg, G. J. (2001), 'The effect of vocational employment training on the individual transition rate from unemployment to work', Swedish Economic Policy Review, 8, 175-213.

Rowold, J. (2007), 'Individual influences on knowledge acquisition in a call center training context in Germany', International Journal of Training and Development, 11, 1, 21-34.

Saraiva, A. (1999), 'Incidência e Impacto Salarial da Formação Profissional em Portugal (Extent and wage impact of training in Portugal)', Economia, 22, 27-43.

Van Praag, B. M. S. and Ferrer-i-Carbonell, A. (2008), Happiness Quantified: A Satisfaction Calculus Approach, Revised edn (Oxford: Oxford University Press).

Van Reenan, J., Reed, H. and Dearden, L. (2006), 'The impact of training on productivity and wages: evidence from British panel data', Oxford Bulletin of Economics and Statistics, 68, 4, 397-421.

Velada, R., Caetano, A., Michel, J. W., Lyons, B. D. and Kavanagh, M. J. (2007), 'The effects of training design, individual characteristics and work environment on transfer of training', International Journal of Training and Development, 11, 4, 282-94.

Vieira, J. C. (1999), 'Returns to education in Portugal', Labour Economics, 6, 4, 535-41.

Wasmer, E., Fredriksson, P., Lamo, A., Messina, J. and Peri, G. (2007), The Macroeconomics of Education in Europe (Oxford: Oxford University Press). 